\title{
Rockefeller and Philanthropy
}

\section{By Willard Connely,}

\author{
Director of the American University Union in London
}

\section{$\mathrm{T}$} HE life of John D. Rockefeller, who died on May 23, was a history of system, not only in the American business of oil, but also in the American business of philanthropy. Whilst Rockefeller was learning how to accumulate money, he was concurrently learning methods by which he should in time give it away. The nearer he approached monopoly, the easier it was for him to retreat to charity. It is because of Rockefeller's skill in the ways of corporations, in planning, shaping and extending them, that the vast 'benevolent trusts' which he created, trusts operated by business men as able as the executives of Standard Oil a generation ago, have become a model of American philanthropic enterprises to-day. That model has stood for 'efficiency in giving'.

These trusts admittedly share leadership in kind with the great Carnegie funds, which originated at almost the same time near the turn of the century. But Rockefeller early set an example to his eminent associates-Harkness, Archbold, Flagler, Folger-in giving money to the public cause. When still other capitalists devised similar charities, capitalists who in the era which Rockefeller dominated had like himself learnt from business the principle of consolidation, there ensued that rise of American philanthropy which has left few corners of the world untouched.

Shortly after the Rockefeller family moved west (1853) from New York State to Cleveland, Ohio, their son, aged about sixteen years, left school, to become a clerk at 4 dollars a week (16s.). Even then he began his lifelong practice of giving. He used to give dimes (5d.) to poor children worth helping. Of every such item Rockefeller kept a record; his meticulous juvenile notebook, which he called 'Ledger A', shows even the deposit of a penny at church. Establishing a commission firm of his own at nineteen years of age, he soon admitted partners, who multiplied his profits. There was in Cleveland an infant industry, the refining of petroleum. Rockefeller saw that if he could get a start in this business, he could make use of the competing transport facilities which Cleveland offered by both rail and water to distribute the oil widely at low cost. By the time he was twenty-eight he had formed the company of Rockefeller, Andrews and Flagler, and had bought a large oil refinery. Three years later, though his personal fortune was only $£ 10,000$, Rockefeller brought into being the Standard Oil Company, eapitalized at

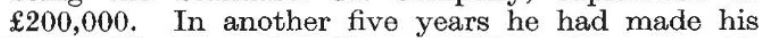
first million pounds. He was thirty-six years old. The rest of the story-the Oil Trust, its dissolution in 1892, its renewed prosperity as a New Jersey corporation, its second dissolution in 1911-is the story as well of the growth of Rockefeller's millions to the point at which he believed he could engage in effective and continuous philanthropies.

In planning his gifts, Rockefeller relied for many years on the advice of the late Frederick Gates, his intimate friend. One result of their collaboration was to place the disposal of capital as well as interest entirely in the hands of self-perpetuating trustees. In this respect the Rockefeller charities differed from other great American foundations. If the trustees decided to liquidate a trust, they could give all the capital away and discontinue the fund. This was recently done in the case of the International Education Board. The policy of Rockefeller in allow. ing absolute discretion to his trustees has been followed by his son, who although one of the trustees, casts only one vote.

Founding his first great benefaction in 1901, ten years before he retired from the presidency of Standard Oil, Rockefeller, while still in the business of accumulating, was able to apply his experience to the business of giving. This first trust was the Institute for Medical Research. He gave it a hospital in New York, and laboratories in New York and in Princeton (New Jersey). Such names as Flexner, Carrel and Noguchi are sufficient to remind one of the quality of work carried out, which has included the discovery of the anti-serum for cerebro-spinal meningitis, and the development of a serum for yellow fever, now in wide use in the tropics, especially by aviators. Huge sums have, of course, been expended as well on the study of cancer, infantile paralysis, and other diseases the mysteries of which are not yet fully solved.

The second trust, created by Rockefeller a few years later, was the General Education Board, designed to assist American universities. Rockefeller from the start had been anxious to help the Negro, particularly in medical education, and the Board contributed heavily to the medical schools of Negro universities in the South: Howard University, in Washington; Maharry Medical College of Fisk University, Tennessee; and Dillard Medical School in New Orleans. But on a wider scale, one of the signal appropriations of this Board was $£ 2,000,000$ for medical schools in general, to ensure a high quality of clinical instruction; schools which specially bene. fitted from this fund were those of Harvard, Yale and Columbia in the east, Johns Hopkins and Vanderbilt in the south, and Chicago and Iowa in the west. Having given medicine this great lift up, the Board turned to the basic sciences, physics, chemistry, biology, and in like manner established them on a sounder footing of research and teaching in important American university centres. Yet perhaps no grant of the General Education Board has been more welcome than the distribution of another $£ 2,000,000$, just after the Great War, to endow and increase salaries in all departments of higher education. The scheme was to match dollar for dollar, though in some cases the scale was one dollar to two, and in still others one to three. Graduates rushed to the call. Under this scheme, 170 American colleges large and small received grants, which needless to say have gone far to transform the quality of their staff.

In 1909 the third trust, the Rockefeller Foundation, came into being, a $£ 20,000,000$ corporation, with the world as its field of effort-c"for the well-being of mankind". The Foundation has co-operated with 
Governments of many countries to combat, for example, hookworm, malaria and yellow fever; and at the same time to institute centres of public health, to promote nursing education, and to develop medical schools. An instance of significant medical benefaction has been the support in large part of the Peking Union Medical College in China ; again, the London School of Hygiene and Tropical Medicine was built and equipped by a gift of half a million sterling. The recent larger gifts of the Foundation in England have been mainly for other than medical purposes, such as funds for the University of London site in Bloomsbury, the grant to the London School of Economics, the grant to Cambridge to include the new library, and about three fifths of the sum needed for the Bodleian extension at Oxford, the foundation stone of which will be laid on June 25 by Queen Mary. The total of these benefactions amounts to $£ 1,872,000$.

In 1929, the trustees of the Foundation, again acting with the free hand which the policy of Rockefeller accorded them, absorbed a fourth trust set up some years earlier by the founder, the Laura Spelman Rockefeller Memorial, named after his wife and dedicated to the aid of the social sciences and to the welfare of children. The work of the whole now comprehends not only the international health division of the Foundation and the social sciences division of the Memorial, but also divisions for medical sciences, natural sciences and the humanities.

A characteristic of the Rockefeller philanthropies is that their practice comes from time to time under systematic review and revision by the trustees. This is done in order to meet the altering social needs of given countries. Vigilant attention to system, at home in the General Education Board and in the Institute for Medical Research, abroad in the Foundation whose work now encompasses the world, is the heritage of the business genius of John D. Rockefeller.

\section{Regularities and Irregularities in the Ionosphere}

$\mathrm{P}^{\mathrm{R}}$ ROF. E. V. APPLETON, in the Bakerian Lecture before the Royal Society, delivered on June 10, surveyed the information derived from radio sounding of the ionized regions of the upper atmosphere and compared the results with those derived from a theory of simple layer formation by solar ionizing radiation, travelling rectilinearly and attenuated according to a massabsorption law. Such a formation is called a 'simple region'. The comparisons are concerned chiefly with the variation of maximum electron content $N_{\mathrm{m}}$ with solar radiation angle of incidence $\chi$, with the total conductivity for direct currents such as determines the quiet-day magnetic variations and with the highfrequency absorption of radio waves traversing such a region, the two latter quantities being, to some extent, related.

For the lower Region $E$, where the daytime recombination is sufficiently rapid to maintain the electron concentration close to the equilibrium value, recombination substantially balancing ionization, the value of $N_{\mathrm{m}}$ is found to vary, experimentally and theoretically, as $(\cos \chi)^{1 / 2}$. The high-frequency absorption for radio transmission, on the other hand, varies theoretically as $(\cos \chi)^{3 / 2}$. Here fair agreement is found with the experimental seasonal noon variation when the sun is high, as in summer, but the winter values show disagreement, the absorption being then greater than simple theory predicts. For the case of the diurnal variation of absorption during a summer day, Best and Ratcliffe, working at Cambridge, have found good agreement with the theoretical relation.

No evidence is found suggesting the existence of permanent highly reflecting regions in the lower or middle atmosphere.

From the high-frequency absorption and other data, the transverse direct-current electron conductivity of a simple region is estimated and found to be less than that calculated by Schuster and Chapman from the magnitude of the magnetic variations, even after allowing for the revised estimates of upper-atmospheric motions recently made by Pekeris. This difficulty is met by the assumption of the existence of quantities of positive and negative ions in the lower part of the ionosphere, undetectable by radio methods, but which contribute to the conductivity for steady electromotive forces. From this assumption follows an explanation of the high effective electron recombination coefficient in the lower region, where the value is high because of the large number of positive ions. There is a marked difference between the day and night values of the effective electron recombination coefficients in Region $E$.

The identification of the lower regions of the ionosphere with the levels at which flow the currents affecting terrestrial magnetism is supported by evidence from systematic measurements of the value of $N_{\max }$, for Regions $E, F_{1}$ and $F_{2}$, which show that the ionization in Regions $E$ and $F_{1}$ varies by about 50 per cent over the sunspot cycle, as does the magnetic variation. The variation of Region $F_{2}$ ionization, on the other hand, exhibits no parallelism with the magnetic changes, either in respect of seasonal or sunspot cycle trends, indicating that the magnetic currents do not flow at high levels.

The two types of ionospheric abnormalities, the one associated with bright solar eruptions and the other with terrestrial magnetic storms, were compared and discussed.

An estimate of the actual heights reached by radio waves at the level of reflection leads, in turn, to an estimate of the proportional variation of air density with height for the ionized component. From the fact that Region $F$ is found to be some four or five times as thick as Region $E$, it follows that the local 'scale-height', $H$, in Region $F$ is correspondingly greater than in Region $E$. The atmosphere therefore extends to much greater heights than are estimated from the simple exponential decrease of pressure with height found in the lower atmosphere. Such an extension of the ionizable gases to great heights indicates either that the temperature at $300 \mathrm{~km}$. is higher than at lower levels, or else that it is there composed largely of a light gas such as helium. Difficulties in the way of the acceptance of the latter alternative are discussed. 